The Effect of the Presence of an Audience on Risk-Taking while Gambling:

The Social Shield

Jérémy E. Lemoine ${ }^{1,2}$ and Christine Roland-Lévy ${ }^{2, *}$

${ }^{1}$ ESCP Europe Business School, London, United-Kingdom

${ }^{2}$ C2S EA 6291, Department of Psychology, University of Reims Champagne-Ardenne, Reims, France

*Corresponding author

Address:

${ }^{1}$ ESCP Europe Business School, 527 Finchley Road, London, NW3 7BG, United-Kingdom

${ }^{2}$ C2S, Laboratory of Psychology: ‘Cognition, Health, Socialization’ EA 6291, University of Reims Champagne-Ardenne, 57 rue Pierre Taittinger, 51096, Reims Cedex, France Phone number:

$1+442074438800$

$2+33326913776$

Emails: jeremy.lemoine@univ-reims.fr, christine.roland-levy@univ-reims.fr 


\title{
The Effect of the Presence of an Audience on Risk-Taking while Gambling:
}

\section{The Social Shield}

\section{Word Count: 4896}

\begin{abstract}
Being in a social context influences risk-taking behavior. This study aims to identify the effect of an audience's presence on risk-taking while gambling. One hundred and thirtytwo university students played a computer roulette game. They were randomly allocated to one of our three conditions: (i) either they played alone; or (ii) in the presence of the experimenter; or (iii) in the presence of the experimenter, while being videotaped. Results revealed a significant effect on risk-taking in the participants with the presence of an audience, with more risk-averse behaviors in the two types of audience conditions than in the alone condition. No differences were found between the two audience conditions. Thus, an audience may prevent risk-taking and provide a social shield.
\end{abstract}

Keywords: Social facilitation; Prospect theory; Risk-taking; Gambling; Audience. 


\section{The Effect of the Presence of an Audience on Risk-Taking while Gambling:}

\section{The Social Shield}

Gambling has become a common behavior in industrialized countries, with about $60 \%$ to $90 \%$ of the adult population who gambles at least occasionally (Giroux, Jacques, Ladouceur, Leclerc, \& Brochu, 2012). The prevalence rate of online gambling is not as frequent. However, according to H2 Gambling Capital (2012), cited in Gainsbury et al. (2015), online gambling increased rapidly from 2004 to 2011 , at a rate of $17 \%$ per year. Consequently, the prevalence of interactive gambling reached 8.1\% in Australia in 2011 (Gainsbury et al., 2014).

Griffiths and colleagues identified several structural and situational differences between offline and online gambling (Griffiths, 2003; McCormack \& Griffiths, 2013), with online gambling leading to higher risk potential among gamblers with gambling disorders (Brosowski, Meyer, \& Hayer, 2012). Among those differences, some have been confirmed, such as the impact of the accessibility of gambling (Griffiths \& Barnes, 2008), while others have just been theorized, including the effect of virtual money versus real money (Griffiths, 1993; Griffiths \& Parke, 2002), or the anonymity and disinhibition offered by the privacy of the Internet (Griffiths, 2003; Suler, 2004).

\section{Social facilitation theory}

As suggested by the early social facilitation literature, people behave differently when they are alone (e.g., when they are gambling online) compared to when they are in the presence of other people (Allport, 1920; Dashiell, 1930; Triplett, 1898). Zajonc's main postulate is that "audience enhances the emission of dominant responses" (Zajonc, 1965, p. 270). In other words, in the presence of observers, the choices and behavior, which have the 
highest probability of occurring, will be favored compared to other choices and behavior with lower occurrences.

Although the social facilitation effect has been widely reproduced across decades and situations (for a meta-analysis, see Bond \& Titus, 1983), there is no consensus around a clear explanation of this phenomenon (for reviews see e.g., Aiello \& Douthitt, 2001; Guerin, 1993). The first explanation came from Zajonc's $(1965,1980)$ drive model, which suggested that the 'mere presence' of others increases the arousal level, which consequently leads to a social facilitation effect. The second explanation is about social comparisons and combines different theories. The evaluation apprehension theory (Cottrell, 1972) suggests that it is the concern of the evaluation which increases an individual's drive. The self-awareness theory (Duval \& Wicklund, 1972) and the control system model (Carver \& Scheier, 1978) explain that people primarily focus on themselves. For the self-awareness theory, they aspire to reduce the gap between their behavior and their personal ideals, while for the control system model they try to perform the task according to a social standard. According to the self-presentation theory (Bond, 1982) people aspire to present themselves as competent. The third explanation describes the presence of others as a distraction, which causes an attention conflict (Baron, 1986). This distraction can be internal, such as thinking about their performance, or external, such as being involved in social comparison. The theories presented above are the main ones in the social facilitation literature, but the list is far from being exhaustive (for a review, see Guerin, 1993).

\section{Social facilitation in gambling}

The social facilitation literature gathers different types of social presence, including co-action, mere presence, and the presence of an audience. Since Zajonc et al.'s (1970) first experiment studying risk-taking in the social facilitation context, only a few studies have examined the influence of social facilitation on gambling behavior. Among those, some 
investigated co-action (e.g., Cole, Barrett, \& Griffiths, 2011; Rockloff \& Dyer, 2007;

Rockloff, Greer, \& Fay, 2011), one investigated the mere presence (Rockloff, Greer, \& Evans, 2012) and one the presence of an audience (Rockloff \& Greer, 2011).

In accordance with Guerin (1993) and Houston, Harris, Moore, Brummett, and Kametani (2005), different types of situations were distinguished on the one hand, situations in which there is an audience, or even the mere presence of an audience, and on the other hand, co-action that is considered here more as a competitive situation in which people have "the desire to beat" the other co-actors (Triplett, 1898, p. 526). In line with Guerin (1986), we also make a distinction between mere presence situations and situations with the presence of an audience. Guerin defined mere presence as situations where "all influences of other persons have been removed except the fact of their presence" (Guerin, 1986, p. 38). In these situations, the audience cannot be in contact with, see or judge the participants. While people who are performing tasks in the presence of an audience can feel that they are being evaluated, those in mere presence situations know that people around them are not aware of their behavior and therefore cannot assess their performance.

In this vein, Cole et al. (2011) conducted an experiment in which the participants gambled in a roulette game, both in an online condition and in an offline condition. They played either alone or in the presence of a confederate acting as another participant. The goal of this experiment was, first of all, to identify the effect of the online situation on risk-taking compared to the offline situation; secondly it aimed at testing the influence of the presence of a co-actor compared to when playing alone. Results suggested that people take more risks in an online situation and that they also take more risks in the presence of another participant.

Rockloff and Greer (2011) and Rockloff et al. (2012) carried out two experiments in which they studied the influence of both the mere presence of people and the presence of an audience on risk-taking behavior while gambling. Both experiments were composed of three 
conditions: playing alone, playing in front of a small audience (composed of 6 people) and playing in front of a larger audience (composed of 26 people). The two experiments varied only in the behavior of the audience. In the mere presence experiment (Rockloff et al., 2012), the audience performed a task under sensory deprivation; in other words, they were blindfolded and had to wear earphones playing music. Therefore, they could not see or hear the participant who was gambling (the participant was aware of the audience's inability to see or hear him/her). In the audience experiment (Rockloff \& Greer, 2011), people in the audience observed the participant while the latter was gambling (in this condition, the participant was aware of being watched and heard by the audience). Results of the mere presence study indicated mixed effects on gambling. These inconsistencies were due to participants' past gambling experiences and to their disorders relating to gambling. In mere presence conditions, gamblers without gambling disorder bet larger amounts but stopped gambling quickly when they were facing losses, whereas gamblers with gambling disorders bet smaller amounts and showed an increase in persistence while they were confronted to losses. In the audience experiment, it was predicted that participants in the alone condition would take lower levels of risk than those in the audience conditions; however, results indicated the opposite effect: the presence of an audience decreased the level of risk-taking. The size of the audience had no effect on the risk-taking behavior. These results were interpreted with two different explanations of the social facilitation theory: Zajonc's (1965) drive theory and Carver and Scheier's (1981) control theory. They suggest that by decreasing their bet-size, gamblers either displayed their dominant response or they conformed to a salient aspect of performance. However, it is still unclear what the dominant response and the salient aspect of performance were for the gamblers. 
The distinction between co-action, the mere presence and the presence of an audience may explain the difference of results between Cole et al. (2011), Rockloff et al. (2012), and Rockloff and Greer (2011).

\section{Prospect theory}

The goal of the experiment presented hereafter was to identify the effect of the presence of an audience on risk-taking behavior while gambling. According to the social facilitation theory, the presence of an audience watching (which is different from a co-action situation in which the audience is also playing) should lead people to adopt the most frequent behavior. Numerous theories have emerged from the economic and the psychological fields to understand and predict people's behavior in risky situations. The one which received the most support and which is, nowadays, the most shared and consensual one, is the prospect theory (Kahneman \& Tversky, 1979; Tversky \& Kahneman, 1992). This theory is conceptualized by describing the ways in which people make decisions in risky situations, even if these decisions are irrational. "It was the first rational theory of irrational behavior" (Wakker, 2010, p. 2). Among all its predictions, prospect theory claims an effect of framing as well as inaccuracies in the estimation of probabilities (i.e., overestimation of small probabilities and underestimation of medium and large probabilities). The prospect theory also postulates that people feel more displeasure after a loss than they enjoy a win (Kahneman, 2003; Kahneman, Knetsch, \& Thaler, 1991; Tversky \& Kahneman, 1991, 1992), and therefore, it states that people tend to be risk averse. Tversky and Kahneman (1991) found that losses are perceived as $2-2.5$ times more strongly than gains. According to the prospect theory, people's most frequent behavior is to be conservative and to take low risk. This postulate is in line with Zajonc et al.'s (1970) results, which showed that people took lower risk when they were in the presence of an audience. Therefore, it was hypothesized that, in a gambling situation, while being observed by an audience, people would take lower risk than when being alone (H1). 
According to Rockloff and Greer's (2011) results, it was also hypothesized that the size of the audience would not influence the behavior (H2). The presence of a small audience, even if it consists of one person only, should be enough to reduce the level of risk-taking.

\section{Methods}

\section{Participants}

One hundred and thirty two non-gamblers or occasional gamblers, who were university students ( 83 females/49 males) from various fields of studies, took part in this study. A power analysis was conducted with G*Power 3.1 (Faul, Erdfelder, Lang, \& Buchner, 2007). It indicated that based on a medium effect size $(f=.25)^{1}$, and an error probability of $.05,132$ participants lead to a power of .72 (which is a little below the .8 threshold (Cohen, 1988, 1992) for which 157 participants would have been required). The respondents' age was between 18 and 31 years, the average age being 21.2 years $(S D=2.4)$. All participants, except one, reported being French ${ }^{2}$. The three fields of study with the highest representation were psychology, sports and language, with 29, 20 and 15 participants respectively. Regarding their education level, 88 participants were currently in the process of obtaining their bachelor's degree, 35 were in a master's program, and two were preparing a PhD. Among the participants, 115 declared that they did not have a job while studying. Regarding their personal income, 66 participants declared receiving less than $€ 12,000$ per year, 15 declared receiving between $€ 12,000$ and $€ 18,000$ per year, while the eight remaining participants declared receiving more than $€ 18,000$ per year $^{3,4}$. Regarding their family income ${ }^{5}, 27$ declared that their family had less than $€ 18,000$ per year; 22 declared that their family earned between $€ 18,000$ and $€ 30,000$ per year; 16 declared that their family earned between $€ 30,000$ and $€ 36,000$ per year; and 13 declared that their family earned more than $€ 36,000$ per year. 


\section{Materials and procedure}

Participants were recruited on campus by one of the authors in order to be part of a study involving gambling. For this experiment, participants were recruited individually and the study took 15 to 20 minutes. After agreeing to take part in the study, participants were accompanied to a room in which they were invited to sit down, facing a computer on which they would play a roulette game. Similar to Dixon, Hayes, and Aban (2000), who also used a simulated roulette game, and to Gehring and Willoughby (2002) - who created a gambling task - a simulated gambling game was used to measure risk-taking. The experimenter explained the rules of the game; the rules were also shown, at all times, on the screen of the computer. Participants had to read the rules before starting the game. The roulette game is a gambling game in which participants have chips that they can use to gamble. This gambling game offers numerous different types of bets with different probabilities of winning and with different payoffs ${ }^{6}$. Participants started the game with 100 chips and were told to try to gather as many chips as possible by the end of the game (after eight rounds). They were free to gamble on any bet they wanted to and to choose, as they wished, their stakes. They could also place several bets at the same time for one round. After reading the rules, each participant had to play at least one practice round in order to help him/her understand the rules and the game's interface; they could perform as many practice rounds as they wanted to. In case they had any question, the experimenter remained with them during that phase. When they felt ready, they could start the (real) game. The game stopped at the end of the $8^{\text {th }}$ round, or before, if they had no more chips. At the end of the experiment, participants answered a sociodemographic questionnaire composed of questions about sex, age, nationality, domain of studies, level of studies, employment status, the level of their personal income, and the level of their family income. They were then debriefed: the purpose of the experiment was explained and the experimenter answered all of their questions. 
The above procedure was the same for all three conditions. However, the audience manipulation was different in the three conditions. (1) In the alone condition, the experimenter left the room after the practice round(s) and the participant remained alone during the game. At the end of the game, the participant had to call back the experimenter who was waiting in the corridor. (2) In the experimenter condition, the experimenter stayed in the room, about 1 meter behind the participant, and watched the participant while he/she was playing. (3) In the camera condition, just after orally explaining the rules, the experimenter asked the participant if the game could be recorded in order to show the video recording to students during a class. In this condition, an indirect presence of an audience was used here, as it has been found that the physical presence of an audience was not mandatory to create the social facilitation effect (Djikic, Chan, \& Peterson, 2007; Feinberg \& Aiello, 2006). If the participant agreed ${ }^{7}$, then the experimenter gave him/her a consent form to sign. The practice phase was not recorded in order to enable the participants to do as many practice rounds as they wanted to and to feel free to ask any question. When the participant had finished the practice round, the experimenter approached with a smartphone, stayed about 1 meter behind the participant and pretended to record the game ${ }^{8}$.

To summarize, the audience manipulation differed in the three conditions. In the alone condition, no one was observing the participant: this condition implied the absence of an audience. In the experimenter condition, only one person (the experimenter) could observed the participant: this condition implied the presence of a small audience ( 1 person). In the camera condition, numerous persons could observed the participant: this condition implied the presence of an indirect large audience (the video recording was to be presented to students during a class). 


\section{Data analyses}

Risk-taking was measured with the risk-taking index designed by Martinez, Le Floch, and Gaffié (2005), adapted from a previous index created by Ladouceur and Mayrand (1986). The risk-taking index (RT, see Appendix 1) takes into account the number of chips wagered (NC), the number of chips left at the time of the bet (CT), as well as the probability of losing (PL).

\section{Results}

\section{Preliminary analyses}

Data screening was conducted to detect outliers and the assumption of normality was tested. The outliers labeling rule (Hoaglin, Iglewicz, \& Tukey, 1986; Tukey, 1977) based on g $=2.2$ (Hoaglin \& Iglewicz, 1987), indicated that 4 participants could be considered as outliers and were therefore deleted from the subsequent analyses. The descriptive statistics associated with the level of risk-taking based on the risk-taking index indicated that the alone condition is associated with the numerically highest level of risk-taking $(M=.14, S D=.12)$, followed by the camera condition $(M=.09, S D=.07)$ and the experimenter condition $(M=.08, S D=$ $.07)$. The skew and the kurtosis of the risk-taking index $\left(\right.$ skewness $_{\text {alone }}=1$, kurtosis $_{\text {alone }}=0.27$; skewness $_{\text {experimenter }}=1.22$, kurtosis $_{\text {experimenter }}=1.53 ;$ skewness $_{\text {camera }}=1.37$, kurtosis $\left._{\text {camera }}=2.83\right)$ were not between -1 and 1 for all conditions, which suggests that the responses are not normally distributed in the three groups (Kline, 2011). Moreover, the assumption of the homogeneity of variances was tested and was found to be non-satisfied based on the observation of the boxplots and on the results of the Levene's $F$ test, $F(2,125)=10.62, p<$ .001 .

\section{Risk-taking index}

The distributions of the results obtained from the three conditions were neither normal nor homogeneous for the risk-taking index. Hence, in order to test the hypothesis stating that 
the presence of an audience (none, small and large audience, referring to alone, experimenter and camera conditions) had an effect on the level of risk-taking, a one-way between-groups ANOVAs with a bootstrap procedure, was performed.

The one-way between-groups ANOVA yielded a statistically significant effect, $F(2$, $125)=3.34, p=.038, \eta^{2}=.05$. Thus, the null hypothesis of no difference between the means was rejected, and $5 \%$ of the variance in risk-taking was accounted by the audience manipulation. To further evaluate the nature of the differences between the means of the three conditions, planned contrasts were conducted (Field, 2013). The first planned contrasts, which compared the presence of an audience against being alone (experimenter $=1$; camera $=1$; alone $=-2$ ), revealed that being in the presence of an audience of any size significantly decreased risk-taking compared to being alone, $t(52)=-2.16, p=.035, d=.45$, with a moderate effect size (Cohen, 1992). The second planned contrasts, which compared the influence of the size of the audience, indicated that being in the presence of a potential large audience did not significantly decrease risk-taking compared to being in the presence of a small audience $($ alone $=0 ;$ experimenter $=1$; camera $=-1), t(85)=-0.22, p=.827, d=.07$.

A bootstrap procedure was used to check if the effect obtained in the ANOVA and the planned contrasts were significant, even if the distributions of the results of the three conditions were not normal and not homogeneous. The results of the bootstrap analyses confirmed that the difference between the alone condition and the two audience conditions on the risk-taking index $\left(M_{\text {audience-no audience }}=.045(\mathrm{BCa} 95 \% \mathrm{CI}=.008, .088), p=.041\right)$ was statistically significant.

\section{Unpacking the risk-taking index}

To appreciate whether the difference of risk-taking due to the presence of an audience was triggered by the number of chips bet, or the type of bets which were chosen, or a combination of both, two t-tests using the presence of an audience as an independent variable 
(i.e., grouping the experimenter and camera conditions against the alone condition) and both the number of chips bet and the probabilities of winning as dependent variables, were conducted. Results suggest that participants in the alone condition tended to bet more chips $\left(\mathrm{M}_{\text {alone }}=34.10\right.$ vs. $\left.\mathrm{M}_{\text {audience }}=24.55\right)$ and choose to gamble on the bets with lower probabilities of winning $\left(\mathrm{M}_{\mathrm{alone}}=32.72 \%\right.$ vs. $\left.\mathrm{M}_{\text {audience }}=36.38 \%\right)$. However, these tendencies are not significant either for the number of chips bet, $t(126)=-1.94, p=.054, d=.40$, or for the type of bets which were chosen, $t(126)=1.74, p=.084, d=.31$.

\section{Discussion}

The study aimed to test the effect of the presence of an audience on risk-taking behavior while gambling. According to the association of both the social facilitation theory and the prospect theory, it was expected that, in a risk-taking situation, people would adopt the most frequent behavior and thus take lower risk in the presence of an audience compared to when being alone (H1). Our results confirmed this first hypothesis; participants, who were in the alone condition, were those who took the highest risk. Further investigation indicates that risk-taking behavior observed in the presence of an audience was not triggered solely by the number of chips bet, nor by the probabilities of winning of the type of bets chosen, but by a combination of these two factors. As in Rockloff and Greer (2011), it was also assumed that the size of the audience would not influence risk-taking behavior (H2). Since the level of risk taking did not differ between the two audience conditions (experimenter and camera conditions), the second hypothesis was also confirmed. There was no difference in terms of risk-taking behavior between the condition in which only one person observed the participants and the condition in which they felt observed by a large group. This result suggests that, in a gambling situation, the size of the audience does not influence risk-taking behavior. The presence of only one person already triggered changes in risk-taking behavior. It indicates that, in a gambling situation, while people are alone, they take higher risk than when they are 
in a social context. This is in line with Rockloff and Greer's (2011) results, which showed that the presence of observers decreased the average bet-size, while improving the final payout.

While gambling, participants could choose the level of risk they wanted to take (from extremely low risk to extremely high risk). In the alone condition, they felt free to play as they wanted to, without being observed. In the other two conditions, they felt observed, either by the experimenter alone, or by a potential large audience composed of people with the same status as their own (students) and the experimenter. In these two conditions, because they were observed, the participants emphasized the most frequent behavior; this implies that, according to the prospect theory (Kahneman \& Tversky, 1979; Tversky \& Kahneman, 1992), they focused more on losses than on gains and behaved in a risk averse manner. Our results, as well as those from Rockloff and Greer (2011), showed that the presence of an audience protects people and leads them to taking smaller risks than when they are alone. In both experiments, the presence of an audience played the role of a shield and protected people from acting in a high-risk manner. Our results are consistent with those of Mishra, Morgan, Lalumiere, and Williams (2010), who investigated the influence of an observer on gambling behavior among male participants. They found a decrease in the time spent gambling when they were observed compared to when they were alone. These results also confirm those from Ladouceur, Jacques, Sévigny, and Cantinotti (2005), who found that isolation while gambling, provides privacy, which can lead to an increase of impaired control.

This study is in line with Hardoon and Derevensky (2001), Noval and Mitchell (2003) and Yechiam, Druyan, and Ert's (2008) research which investigated the influence of social contexts on risky gambling behavior. However, this paper differs from the previous ones since it examines the effect of the presence of an audience on risk-taking behavior in a gambling situation. While Hardoon and Derevensky (2001) and Yechiam et al. (2008) studied the influence of co-action on gambling behavior, and Noval and Mitchell (2003) focused on the 
influence of the relationship with the person watching (i.e., friends or strangers), here, the influence of an audience on gambling behavior was investigated through the variation of the social context in three different conditions. The standard deviation of the responses of the participants in the alone condition was bigger than the ones in the audience conditions. Moreover, the kurtosis of the risk-taking index was lower in the alone condition than in the two audience conditions. It implies that for the alone condition, there are more participants in the tails of the distribution, while for the audience conditions more participants are located in the peak of the distributions (Garson, 2012). This indicates that the behavior of participants tends to be more homogeneous when they are in the two audience conditions than in the alone condition. According to Zajonc $(1965,1980)$, in the audience conditions tested in this study, people have been subject to social facilitation and behaved according to the dominant response. On the contrary, in the alone condition, the way in which they behaved tends to be more heterogeneous.

We did not measure gambling experience and potential disorder associated to gambling among our participants, which is the main limitation of this experiment. Indeed, Rockloff et al. (2012) found an interaction between being in a social context, characterized by the mere presence of an audience, and the fact that their participants had gambling disorders on risk-taking behavior.

Another limitation of this study is connected to the two audience conditions, it is possible that the results would have been different if the audience had been represented only by people having the same status. Nevertheless, since Ekdahl's work (1929), most of the studies (e.g., Carver \& Scheier, 1981; Fraser, 1953) have found an effect in terms of social facilitation when using the experimenter as an audience (Guerin, 1993).

According to the Goal-Setting Theory (Locke, Latham, \& Erez, 1988) or the Reinforcement Theory (Komaki, Coombs, \& Schepman, 1996), the absence of money could 
be seen as an additional limitation. However, in line with the Self-Determination Theory (Deci, 1971; Deci \& Ryan, 1985), and a review by Camerer and Hogarth (1999), financial incentives are not necessary to motivate participants to do a certain task correctly and to perform well. Nevertheless, it would be interesting to test the effect of money in this context, as risk-taking could be more realistic if it involved losing real money rather than chips.

Gainsbury and Blaszczynski (2011) found comparable results for their two samples of regular electronic gaming machine players (university students and venue gamblers), although they observed some discrepancies between the two groups (e.g., greater effect sizes in the student population). Therefore, the composition of our sample, university students, limits the generalization of the results of this study to the general population.

As in other experiments involving risk-taking in gambling (e.g., Ladouceur \& Mayrand, 1987; Martinez, Le Floch, Gaffié, \& Villejoubert, 2011), we used the roulette game. It was observed that some participants used specific strategies: betting alternatively on black or red, or betting on the same combination at each round and increasing their bets after each loss, and so on. The use of strategies may have reduced the impact of the context because people might have used the same strategies whatever the context is.

Our population was composed of university students who were either non-gamblers, or occasional gamblers, and it would be interesting in a new study to investigate the effect of the presence of an audience on gamblers with and without gambling disorders from the general population. Recent work on gamblers' perceptions and representations of gambling established differences between gamblers with and without gambling disorders (Lemoine, Kmiec, \& Roland-Lévy, 2017; Spurrier, Blaszczynski, \& Rhodes, 2014). It is possible that gamblers with gambling disorders would feel the pressure of the audience in a different manner. However, in this case, it would also be useful to use an unknown game, rather than the roulette one, in order to avoid the use of previously known strategies. Furthermore, it 
would be interesting to include the possibility of winning or of losing money in order to establish the ecological validity of the results.

The findings of this study suggest that besides the impact of the accessibility of gambling (Griffiths \& Barnes, 2008), online gambling possesses features that make it more risky than offline gambling. Our results support the fact that social contexts influence gambling behavior and reduce the propensity to take risk. The anonymity and disinhibition offered by the privacy of the Internet (Griffiths, 2003; Suler, 2004) influence gambling behavior. Our research study provides an interesting contribution to the knowledge of gambling; it offers clues on how to orient policy and practice to limit the risk of online gambling: reducing anonymity of the Internet, increasing scrutiny, implementing controls that regulate use (Wood \& Williams, 2007), and setting credit limits (Smeaton \& Griffiths, 2004). Anonymity of the Internet could be reduced by requiring ID to register on the gambling service providers, and by creating a profile with the person's real name and photo. Scrutiny could be increased by displaying a message indicating that their bets are recorded by the service provider. Implementing time and frequency limits could increase control over the overall expenses (Wood \& Williams, 2007); this could increase scrutiny as well. Finally, imposing credit limits could also reduce the overall expenses (Smeaton \& Griffiths, 2004).

\section{Conclusion}

Past research on the effects of social facilitation on risk-taking, as well as the results found in this study, suggest that the presence of an audience leads to more cautious behavior and reduces the level of risk-taking. The audience plays the role of a social shield, while online gambling offers gamblers the privacy of the Internet, which may lead to potential higher risk-taking among gamblers, especially for those with gambling disorders (Brosowski et al., 2012; Griffiths, 2003). 


\section{Notes}

${ }^{1}$ We estimated the effect size required for this study based on the results from Rockloff and Greer (2011). Although they used a different game and a different measure of risk-taking, their experiment is the most similar one to the one presented in this study. The effect size was not reported in their manuscript, however; we computed an approximate effect size based on the F-value, the means (retrieved from Figure 3) and the sample sizes of the three groups, using a calculator available on Wilson's website and we found $d=0.47$.

${ }^{2}$ The nationality was not taken into account in the analyses.

${ }^{3}$ This result may be explained by the fact that most of them do not have a regular job, and get their main income from scholarships or from their family.

${ }^{4}$ The two questions regarding the income were not mandatory, which explains why the number of participants on these questions is lower than the total number of participants.

${ }^{5}$ Family income corresponds to the sum of their personal income and the income of whom they consider as being member of their family (parents or spouse).

${ }^{6}$ A table with the description of bets with the probabilities of winning and the relative payoffs were visible on the screen during the whole game. Thus, participants knew exactly the characteristics of the different bets and decisions could be considered as decisions made under risk rather than decisions made under uncertainty (e.g., Ellsberg, 1961; Knight, 1921).

${ }^{7}$ Two participants did not agree, therefore the experiment was conducted as in the experimenter condition, but their results were not kept for the analyses.

${ }^{8}$ The experimenter acted in order to make participants genuinely believe that they were being video recorded (i.e., he asked them to adjust the screen so it would be more visible on the camera; he also asked them to sit a bit more on the left side so that they would not obscure a part of the screen; and he told them when he started recording so that they could 
begin to play). During the debriefing, participants in the camera condition were asked how they felt about being recorded while playing. All participants in the camera condition declared that they really thought that the session was recorded. However, the content of the debriefing was not properly measured. The purpose was to make sure that all the participants genuinely believed that they were being recorded and to delete the data of those who expressed doubts.

\section{Disclosure statement}

No potential conflict of interest was reported by the authors. 


\section{References}

Aiello, J. R., \& Douthitt, E. A. (2001). Social facilitation from Triplett to electronic performance monitoring. Group Dynamics: Theory, Research, and Practice, 5(3), 163-180. doi: 10.1037/1089-2699.5.3.163

Allport, F. H. (1920). The influence of the group upon association and thought. Journal of Experimental Psychology, 3(3), 159-182. doi: 10.1037/h0067891

Baron, R. S. (1986). Distraction-conflict theory: Progress and problems. Advances in Experimental Social Psychology, 19(1986), 1-39. doi: 10.1016/s0065-2601(08)60211-7

Bond, C. F. (1982). Social facilitation: A self-presentational view. Journal of Personality and Social Psychology, 42(6), 1042-1050. doi: 10.1037/0022-3514.42.6.1042

Bond, C. F., \& Titus, L. J. (1983). Social facilitation: a meta-analysis of 241 studies. Psychological Bulletin, 94(2), 265-292. doi: 10.1037/0033-2909.94.2.265

Brosowski, T., Meyer, G., \& Hayer, T. (2012). Analyses of multiple types of online gambling within one provider: an extended evaluation framework of actual online gambling behaviour. International Gambling Studies, 12(3), 405-419. doi: 10.1080/14459795.2012.698295

Camerer, C. F., \& Hogarth, R. M. (1999). The effects of financial incentives in experiments: A review and capital-labor-production framework. Journal of Risk and Uncertainty, 19(1-3), 7-42. doi: 10.1007/97894-017-1406-8_2

Carver, C. S., \& Scheier, M. F. (1978). Self-focusing effects of dispositional self-consciousness, mirror presence, and audience presence. Journal of Personality and Social Psychology, 36(3), 324-332. doi: 10.1037/0022-3514.36.3.324

Carver, C. S., \& Scheier, M. F. (1981). The self-attention-induced feedback loop and social facilitation. Journal of Experimental Social Psychology, 17(6), 545-568. doi: 10.1016/0022-1031(81)90039-1

Cohen, J. (1988). Statistical power analysis for the behavioral sciences (2 ed.). New York: Academic press.

Cohen, J. (1992). A power primer. Psychological Bulletin, 112(1), 155-159. doi: 10.1037/0033-2909.112.1.155

Cole, T., Barrett, D. J., \& Griffiths, M. D. (2011). Social facilitation in online and offline gambling: A pilot study. International Journal of Mental Health and Addiction, 9(3), 240-247. doi: 10.1007/s11469-0109281-6

Cottrell, N. B. (1972). Social facilitation. In C. G. McClintock (Ed.), Experimental social psychology (pp. 185236). New York: Holt, Rinehart \& Winston.

Dashiell, J. F. (1930). An experimental analysis of some group effects. The Journal of Abnormal and Social Psychology, 25(2), 190-199. doi: 10.1037/h0075144

Deci, E. L. (1971). Effects of externally mediated rewards on intrinsic motivation. Journal of Personality and Social Psychology, 18(1), 105-115. doi: 10.1037/h0030644

Deci, E. L., \& Ryan, R. M. (1985). Intrinsic motivation and self-determination in human behavior. New York: Plenum.

Djikic, M., Chan, I., \& Peterson, J. B. (2007). Reducing memory distortions in egoistic self-enhancers: Effects of indirect social facilitation. Personality and Individual Differences, 42(4), 723-731. doi: 10.1016/j.paid.2006.08.012

Dixon, M. R., Hayes, L. J., \& Aban, I. B. (2000). Examining the roles of rule following, reinforcement, and preexperimental histories on risk-taking behavior. The Psychological Record, 50(4), 687-704. doi: $10.1007 / \mathrm{bf} 03395378$

Duval, S., \& Wicklund, R. A. (1972). A theory of objective self awareness. New York: Academic Press.

Ekdahl, A. G. (1929). The effect of attitude on free word association-time. Genetic Psychology Monographs, 5, 253-338.

Ellsberg, D. (1961). Risk, ambiguity, and the Savage axioms. The Quarterly Journal of Economics, 75(4), 643669. doi: $10.2307 / 1884324$

Faul, F., Erdfelder, E., Lang, A.-G., \& Buchner, A. (2007). G* Power 3: A flexible statistical power analysis program for the social, behavioral, and biomedical sciences. Behavior Research Methods, 39(2), 175 191. doi: 10.3758/bf03193146

Feinberg, J. M., \& Aiello, J. R. (2006). Social facilitation: A test of competing theories. Journal of Applied Social Psychology, 36(5), 1087-1109. doi: 10.1111/j.0021-9029.2006.00032.x

Field, A. (2013). Discovering statistics using IBM SPSS Statistics: and sex and drugs and rock ' $n$ ' roll (4 ed.). London: Sage.

Fraser, D. (1953). The relation of an environmental variable to performance in a prolonged visual task. Quarterly Journal of Experimental Psychology, 5(1), 31-32. doi: 10.1080/17470215308416621

Gainsbury, S. M., \& Blaszczynski, A. (2011). The appropriateness of using laboratories and student participants in gambling research. Journal of Gambling Studies, 27(1), 83-97. doi: 10.1007/s10899-010-9190-4 
Gainsbury, S. M., Russell, A., Hing, N., Wood, R., Lubman, D., \& Blaszczynski, A. (2015). How the Internet is changing gambling: Findings from an Australian prevalence survey. Journal of Gambling Studies, 31(1), 1-15. doi: 10.1007/s10899-013-9404-7

Gainsbury, S. M., Russell, A., Hing, N., Wood, R., Lubman, D. I., \& Blaszczynski, A. (2014). The prevalence and determinants of problem gambling in Australia: assessing the impact of interactive gambling and new technologies. Psychology of Addictive Behaviors, 28(3), 769-779. doi: 10.1037/a0036207

Garson, G. D. (2012). Testing statistical assumptions. Asheboro, NC: Statistical Associates Publishing.

Gehring, W. J., \& Willoughby, A. R. (2002). The medial frontal cortex and the rapid processing of monetary gains and losses. Science, 295(5563), 2279-2282. doi: 10.1126/science.1066893

Giroux, I., Jacques, C., Ladouceur, R., Leclerc, M., \& Brochu, P. (2012). Prévalence des habitudes de jeu en Gaspésie et aux Îles-de-la-Madeleine en 2009 [Prevalence of the habits of game in Gaspésie and in the Îles-de-la-Madeleine in 2009]. Canadian Journal of Psychiatry, 57(3), 192-199.

Griffiths, M. D. (1993). Fruit machine gambling: The importance of structural characteristics. Journal of Gambling Studies, 9(2), 101-120. doi: 10.1007/bf01014863

Griffiths, M. D. (2003). Internet gambling: Issues, concerns, and recommendations. CyberPsychology \& Behavior, 6(6), 557-568. doi: 10.1089/109493103322725333

Griffiths, M. D., \& Barnes, A. (2008). Internet gambling: An online empirical study among student gamblers. International Journal of Mental Health and Addiction, 6(2), 194-204. doi: 10.1007/s1 1469-007-9083-7

Griffiths, M. D., \& Parke, J. (2002). The social impact of internet gambling. Social Science Computer Review, 20(3), 312-320. doi: 10.1177/089443930202000308

Guerin, B. (1986). Mere presence effects in humans: A review. Journal of Experimental Social Psychology, 22(1), 38-77. doi: 10.1016/0022-1031(86)90040-5

Guerin, B. (1993). Social facilitation. Cambridge: Cambridge University Press.

Hardoon, K. K., \& Derevensky, J. L. (2001). Social influences involved in children's gambling behavior. Journal of Gambling Studies, 17(3), 191-215. doi: 10.1023/A:1012216305671

Hoaglin, D. C., \& Iglewicz, B. (1987). Fine-tuning some resistant rules for outlier labeling. Journal of the American Statistical Association, 82(400), 1147-1149. doi: 10.2307/2289392

Hoaglin, D. C., Iglewicz, B., \& Tukey, J. W. (1986). Performance of some resistant rules for outlier labeling. Journal of the American Statistical Association, 81(396), 991-999. doi: 10.2307/2289073

Houston, J. M., Harris, P., Moore, R., Brummett, R., \& Kametani, H. (2005). Competitiveness among Japanese, Chinese, and American undergraduate students. Psychological Reports, 97(1), 205-212. doi: 10.2466/pr0.97.5.205-212

Kahneman, D. (2003). Maps of bounded rationality: Psychology for behavioral economics. The American Economic Review, 93(5), 1449-1475. doi: 10.1257/000282803322655392

Kahneman, D., Knetsch, J. L., \& Thaler, R. H. (1991). Anomalies: The endowment effect, loss aversion, and status quo bias. The Journal of Economic Perspectives, 5(1), 193-206. doi: 10.1257/jep.5.1.193

Kahneman, D., \& Tversky, A. (1979). Prospect theory: An analysis of decision under risk. Econometrica: Journal of the Econometric Society, 47(2), 263-291. doi: 10.2307/1914185

Kline, R. B. (2011). Principles and practice of structural equation modeling (3 ed.). New York: Guilford.

Knight, F., H. (1921). Risk, uncertainty and profit. New-York: Hart, Schaffner \& Marx.

Komaki, J. L., Coombs, T., \& Schepman, S. (1996). Motivational implications of reinforcement theory. In R. M. Steers, L. W. Porter, \& G. A. Bigley (Eds.), Motivation and leadership at work (pp. 34-52). New York: McGraw-Hill.

Ladouceur, R., Jacques, C., Sévigny, S., \& Cantinotti, M. (2005). Impact of the format, arrangement and availability of electronic gaming machines outside casinos on gambling. International Gambling Studies, 5(2), 139-154. doi: 10.1080/14459790500303121

Ladouceur, R., \& Mayrand, M. (1986). Caractéristiques psychologiques de la prise de risque monétaire des joueurs et des non-joueurs à la roulette [Psychological characteristics of monetary risk-taking of gamblers and non-gamblers in a roulette game]. International Journal of Psychology, 21(1-4), 433-443. doi: $10.1080 / 00207598608247600$

Ladouceur, R., \& Mayrand, M. (1987). The level of involvement and the timing of betting in roulette. The Journal of Psychology, 121(2), 169-176. doi: 10.1080/00223980.1987.9712654

Lemoine, J., Kmiec, R., \& Roland-Lévy, C. (2017). Characterization of controlled gamblers and pathological gamblers using the social representation theory. Revue Européenne de Psychologie Appliquée, 67(1), 13-23. doi: 10.1016/j.erap.2016.12.002

Locke, E. A., Latham, G. P., \& Erez, M. (1988). The determinants of goal commitment. Academy of Management Review, 13(1), 23-39. doi: 10.5465/amr.1988.4306771

Martinez, F., Le Floch, V., \& Gaffié, B. (2005). Lien entre perception de contrôle et prise de risque dans un jeu de hasard: Quand l'annonce d'un gain d'autrui intervient [Link between control perception and risk- 
taking in a gambling game: When reports win annoucement take place]. Revue Internationale de Psychologie Sociale, 18(3), 129-151.

Martinez, F., Le Floch, V., Gaffié, B., \& Villejoubert, G. (2011). Reports of wins and risk taking: an investigation of the mediating effect of the illusion of control. Journal of Gambling Studies, 27(2), 271285. doi: 10.1007/s10899-010-9204-2

McCormack, A., \& Griffiths, M. D. (2013). A scoping study of the structural and situational characteristics of internet gambling. International Journal of Cyber Behavior, Psychology and Learning, 3(1), 29-49. doi: 10.4018/ijcbpl.2013010104

Mishra, S., Morgan, M., Lalumiere, M. L., \& Williams, R. J. (2010). Mood and audience effects on video lottery terminal gambling. Journal of Gambling Studies, 26(3), 373-386. doi: 10.1007/s10899-009-9158-4

Noval, J., \& Mitchell, Z. (2003). The wheel of misfortune: Using gambling to assess the link between risky behavior and attachment. Colgate University Journal of the Sciences, 35, 157-168.

Rockloff, M. J., \& Dyer, V. (2007). An experiment on the social facilitation of gambling behavior. Journal of Gambling Studies, 23(1), 1-12. doi: 10.1007/s10899-006-9042-4

Rockloff, M. J., \& Greer, N. (2011). Audience influence on EGM gambling: The protective effects of having others watch you play. Journal of Gambling Studies, 27(3), 443-451. doi: 10.1007/s10899-010-9213-1

Rockloff, M. J., Greer, N., \& Evans, L. G. (2012). The effect of mere presence on electronic gaming machine gambling. Journal of Gambling Issues, 27. doi: 10.4309/jgi.2012.27.11

Rockloff, M. J., Greer, N., \& Fay, C. (2011). The social contagion of gambling: How venue size contributes to player losses. Journal of Gambling Studies, 27(3), 487-497. doi: 10.1007/s10899-010-9220-2

Smeaton, M., \& Griffiths, M. (2004). Internet gambling and social responsibility: An exploratory study. CyberPsychology \& Behavior, 7(1), 49-57. doi: 10.1089/109493104322820110

Spurrier, M., Blaszczynski, A., \& Rhodes, P. (2014). Gambler risk perception: A mental model and grounded theory analysis. Journal of Gambling Studies, 31(3), 887-906. doi: 10.1007/s10899-013-9439-9

Suler, J. (2004). The online disinhibition effect. CyberPsychology \& Behavior, 7(3), 321-326. doi: $10.1089 / 1094931041291295$

Triplett, N. (1898). The dynamogenic factors in pacemaking and competition. The American Journal of Psychology, 9(4), 507-533. doi: 10.2307/1412188

Tukey, J. W. (1977). Exploratory data analysis. Reading, MA: Addison-Wesley.

Tversky, A., \& Kahneman, D. (1991). Loss aversion in riskless choice: A reference-dependent model. The Quarterly Journal of Economics, 106(4), 1039-1061. doi: 10.2307/2937956

Tversky, A., \& Kahneman, D. (1992). Advances in prospect theory: Cumulative representation of uncertainty. Journal of Risk and Uncertainty, 5(4), 297-323. doi: 10.1007/bf00122574

Wakker, P. P. (2010). Prospect theory: For risk and ambiguity. Cambridge: Cambridge University Press.

Wilson, D. B. Practical meta-analysis effect size calculator. Retrieved 22/03/2016, from https://www.campbellcollaboration.org/escalc/html/EffectSizeCalculator-Home.php

Wood, R. T., \& Williams, R. J. (2007). Problem gambling on the internet: implications for internet gambling policy in North America. New Media \& Society, 9(3), 520-542. doi: 10.1177/1461444807076987

Yechiam, E., Druyan, M., \& Ert, E. (2008). Observing others' behavior and risk taking in decisions from experience. Judgment and Decision Making, 3(7), 493-500.

Zajonc, R. B. (1965). Social facilitation. Science, 149(3681), 269-274. doi: 10.1126/science.149.3681.269

Zajonc, R. B. (1980). Feeling and thinking: Preferences need no inferences. American Psychologist, 35(2), 151175. doi: 10.1037/0003-066x.35.2.151

Zajonc, R. B., Wolosin, R. J., Wolosin, M. A., \& Loh, W. D. (1970). Social facilitation and imitation in group risk-taking. Journal of Experimental Social Psychology, 6(1), 26-46. doi: 10.1016/00221031(70)90074-0 
Appendix Risk taking index (Martinez et al., 2005)

$$
R T=\sum \frac{N C * P L}{C T}
$$

Note. $R T=$ risk-taking index; $N C=$ the number of chips wager; $C T=$ the number of chips left at the time of the bet; $P L=$ the probability of losing. 